\title{
Endophytic Fungal Mutualists: Seed-Borne Stagonospora Spp. Enhance Reed Biomass Production in Axenic Microcosms
}

\author{
Michael Ernst, Kurt W. Mendgen, and Stefan G. R. Wirsel \\ Lehrstuhl Phytopathologie, Fachbereich Biologie, Universität Konstanz, Universitätstr. 10, D-78457 Konstanz, Germany \\ Submitted 4 November 2002. Accepted 14 February 2003.
}

\begin{abstract}
Fungal endophytes mainly belong to the phylum Ascomycota and colonize plants without producing symptoms. We report on the isolation of seed-borne fungal endophytes from Phragmites australis (common reed) that were ascribed to the genus Stagonospora. Nested polymerase chain reaction (PCR) assays revealed that a Stagonospora sp. regularly colonized reed as shown for a period of three years. In spring, it was only detected in roots, whereas in autumn, it could frequently be found in all organs, including seeds. Microcosm experiments revealed that seeds harbored viable propagules of the fungus that colonized the developing germling, indicating vertical transmission. Endophytic growth was confirmed by immunofluorescence microscopy, reisolation of the fungus after surface sterilization, and PCR. Aseptic microcosms were established for studying fungal contributions towards host vitality. Several Stagonospora isolates enhanced reed biomass. Seed-borne endophytic Stagonospora spp. thus can provide improved vigor to common reed, which could be most important when seed-derived germlings establish new reed stands.
\end{abstract}

Additional keywords: ITS phylogeny, Phaeosphaeria.

Fungi living in close association with plants can have effects on their host that range from detrimental to beneficial, depending on the partners involved and additional biotic and abiotic factors. Mycorrhiza is a well-documented type of a symbiotic interaction that is found at roots of the majority of higher plants. It is well known that mycorrhizal fungi are important for retrieving nutrients from soil and allocating them to their hosts (Hodge et al. 2001; Landeweert et al. 2001; Sharma et al. 1997). Endophytes represent another type of a putative symbiotic interaction between fungi and plants. Endophytes live within plant tissue without producing overt symptoms. Endophytic fungi have been recovered from all vegetative organs and from a broad range of plants growing from tropical to alpine habitats, indicating that these associations are widespread in nature (Carroll 1988; Petrini et al. 1992). Endophytes represent a wide taxonomical range of fungi, mostly within the phylum Ascomycota. Caroll (1988) distinguished two types of endophytic mutualism. Constitutive endophytic mutualism is

Corresponding author: S. G. R. Wirsel: Institut für Pflanzenzüchtung und Pflanzenschutz, Martin-Luther-Universität Halle-Wittenberg, LudwigWucherer-Str. 2, D-06099 Halle (Saale), Germany; Telephone: +49 345 5522671; Fax:+49 345 5527120; E-mail: wirsel@ landw.uni-halle.de.

Nucleotide sequence data reported are available in the EMBL database under accession numbers AJ496625 to AJ496633. typified by a systemic infection of grasses in genera Festuca, Lolium, and a few others in the family Poaceae with fungi of the anamorph genus Neotyphodium and the corresponding teleomorph genus Epichlö̈ (family Clavicipitaceae, phylum Ascomycota) (Schardl 2001). These fungi proliferate in infected plants and are often vertically transmitted by seeds to the next generation of the host. It has been shown that these fungi improve the vitality of their hosts by increasing resistance against grazing, insects, drought, and microbial parasites (Clay 1992; Leuchtmann 1992; Schardl 2001). Furthermore, they improve biomass production and nutrient status (Arachevaleta et al. 1989; Groppe et al. 1999; Latch et al. 1985; Malinowski et al. 2000). On the other hand, Caroll (1988) characterized inducible endophytic mutualism as a loose association between a host and a fungus. Here, host tissues are colonized by more localized infections that can originate from several different fungi. Although wide-spread in nature, effects of these endophytes on host performance have remained vague.

We investigate the interaction of fungi with common reed (Phragmites australis [Cav.] Trin. ex Steudel, family Poaceae), which often forms homogenous belts at freshwater lakes such as Lake Constance (Germany). In the present work, we have isolated seed-borne endophytes from $P$. australis, studied their occurrence in natural habitats, and demonstrated their influence on host vitality.

\section{RESULTS}

Isolation and characterization

of fungi from seeds of $\boldsymbol{P}$. australis.

We intended to prevent fungal outgrowth on malt agar plates that originated from propagules on the surface of seeds by establishing surface-sterilization procedures that considerably reduced total colony counts (Table 1). To retrieve fungal endophytes from seeds, treatments with $70 \% \mathrm{EtOH}$ (1 min), 5\% $\mathrm{NaOCl}(2 \mathrm{~min})$ and, again, $70 \% \mathrm{EtOH}(1 \mathrm{~min})$ were used (Table $1)$. DNA sequencing of polymerase chain reaction (PCR) fragments generated with primers ITS1F and ITS4 on fungal genomic DNA revealed four different sequences among the 13 isolates obtained from 598 seeds. BLAST searches showed that three sequences matched references in the fungal genus Stagonospora and its corresponding teleomorph Phaeosphaeria, whereas the fourth matched in genus Epicoccum. Stagonospora spp. represented the majority of our isolates, i.e., six were of the 4/99-1 sequence type, four of the 4/99-5 type, and one was of the 4/99-18 type, respectively, whereas Epicoccum $\mathrm{sp}$. was represented by two isolates that were not further used in the present work. We established a molecular phylogeny based 
on the complete internal transcribed spacer (ITS) region of the three Stagonospora sequences to determine the relationships among them and to those of references that were retrieved from GenBank or that were newly established during this study. Recently, the taxonomy of Stagonospora has been reevaluated, confirming a close connection to teleomorphs in Phaeosphaeria (Cunfer and Ueng 1999). The phylogeny demonstrated that the three Stagonospora sequence types originating from reed seeds represent three different species (Fig. 1). Stagonospora sp. (4/991 type) was $100 \%$ identical to one of the references, i.e., Stagonospora neglecta CBS 343.86. The sequence of Stagonospora sp. (4/99-5 type) clustered with a group of highly similar entries, with Phaeosphaeria culmorum CBS 569.86 and P. insignis CBS 579.86 being the closest with $99.6 \%$. The third, Stagonospora sp. (4/99-18 type), was $95.4 \%$ identical to $P$. pontiformis CBS 589.86. In addition to their molecular characterization, we also attempted to induce sporulation of our isolates on several media and under different temperature and light regimes for morphological identification (data not shown). This was successful for 4/99-5 and 4/99-18 but not for 4/99-1, which confirmed the former two as Stagonospora spp.

\section{Detection of a Stagonospora sp. in field samples.}

We developed a nested-PCR assay targeting the ITS region of the species most often isolated, Stagonospora sp. (4/99-1 type), to monitor its presence in different organs of $P$. australis growing in natural habitats. Its specificity was tested by reactions with genomic DNA from several fungi as template and with DNA from the same lot of seeds in which the fungi originated. As expected, the first PCR step using primers targeting all fungi produced bands with all templates (Fig. 2A). By contrast, the second PCR step using primers directed against 4/991 produced only bands with seed DNA and that of the target but not with DNA from Stagonospora spp. strains 4/99-5 and 4/99-18 and Epicoccum sp. strain 4/99-12 serving as negative controls (Fig. 2B). The sensitivity of the assay was determined by mixing serial dilutions of genomic DNA from strain 4/99-1 with constant amounts of host DNA that had been isolated from an aseptically grown microcosm, i.e., one that did not harbor any fungi (see below). We were able to detect about 4 fg of DNA from the targeted fungus (Fig. 2C), which corresponds to about 10 ITS copies when assuming a genome size of 30 megabases.

We harvested 70 plants over a period of three years at four sites at six different times of the season, to investigate whether the targeted fungus originally isolated from seeds would also occur in other organs of the host and, if so, to reveal the temporal and spatial extent of its persistence. General amplificability of 252 DNA preparations from tissue samples representing different organs of those field samples was controlled by an addi- tional PCR assay that targeted the ITS region of $P$. australis (data not shown). These DNAs were then subjected to nestedPCR assays targeting 4/99-1. In general, this fungus was detectable over a period of three years in all organs at all sites and throughout the growth period, when looking at these factors separately. However, there were differences regarding infection frequencies in different organs at different times (Fig. 3). In April, when new shoots just start to emerge, the fungus was only detectable in roots and at low frequency. Progression of the growing season increased its detectability in all organs so that, by September, it appeared to be present in most leaf and stem samples. There were no major differences in total occurrences between the four sites analyzed (data not shown). Sequencing of six of these PCR bands (one root, one rhizome, one stem, two leaves, and one seed sample) proved identity to the 4/99-1 sequence in each case. Mature seeds were only harvested in November and were analyzed in pools of about 200 seeds representing a site, i.e., originated from about 10 plants. Every pool tested yielded the expected PCR product (Fig. 3). In addition, we individually analyzed 96 seeds from 67 plants harvested in two years from four sites at Lake Constance. Detection frequencies ranged from over $80 \%$ to about $10 \%$. On average, $30 \%$ of individual seeds produced a PCR signal, or $36 \%$ of the plants analyzed (data not shown). We observed some variation with respect to year and site. The samples did not show fungal stroma formation as it had been reported for some Epichlö endophytes causing "choke disease" (Schardl and Clay 1997). We do not yet know if seeds that did not produce a signal carried one of the other fungi that we had initially isolated from seeds as well (discussed above).

\section{Detection \\ of a Stagonospora sp. in in vitro-grown germlings.}

Both the isolation of the fungus and the PCR assays on field samples indicated that Stagonospora sp. (4/99-1 type) is carried by seeds of its host. We investigated whether seeds harbor viable propagules that are able to grow into the developing germling. Seeds harvested from Lake Constance habitats were surface-sterilized by treating them as described above. In addition, we included an untreated control. After 9 weeks of growth under sterile conditions, 21 plantlets were harvested for each group and were cut into three parts, the roots and the lower and upper halves of the green parts, respectively. We took care to exclude the hypocotyls with remains of the seed. The samples were further divided to obtain material for DNA isolation and for immunolocalization studies (discussed below). Resulting DNA preparations were analyzed by the nested-PCR assay targeting 4/99-1. Apparently, the fungus did colonize the seedlings (Fig. 4). Its detectability in roots reflected about the frequency at which it had been detected in the particular seed lot

Table 1. Sterilization of seeds from Phragmites australis

\begin{tabular}{|c|c|c|c|c|}
\hline \multirow[b]{2}{*}{ Treatment $^{\mathrm{a}}$} & \multicolumn{2}{|c|}{ Lake Constance seeds } & \multicolumn{2}{|c|}{ Commercial seeds } \\
\hline & $\mathrm{CFU}[\%]^{\mathrm{b}}$ & Germination $[\%]^{\mathrm{c}}$ & $\mathrm{CFU}[\%]^{\mathrm{b}}$ & Germination [\%] ${ }^{\mathrm{c}}$ \\
\hline $\mathrm{H}_{2} \mathrm{O}, 15$ min & 100.0 & 15.7 & 12.8 & 55.3 \\
\hline $5 \% \mathrm{NaOCl}, 4 \mathrm{~min}$ & 45.5 & n.d. & n.d. & n.d. \\
\hline $70 \% \mathrm{EtOH}, 4 \mathrm{~min}$ & 20.9 & n.d. & n.d. & n.d. \\
\hline $\mathrm{EtOH} / \mathrm{NaOCl} / \mathrm{EtOH}$ 1/2/1 min & 2.2 & 19.5 & 0.5 & 87.4 \\
\hline $\mathrm{EtOH} / \mathrm{NaOCl} / \mathrm{EtOH}$ 5/5/5 min & 0.6 & 12.9 & 0.0 & 36.1 \\
\hline $\mathrm{EtOH} / \mathrm{NaOCl} / \mathrm{EtOH}$ 10/10/10 min & 0.5 & 0.0 & n.d. & n.d. \\
\hline $\mathrm{H}_{2} \mathrm{O}, 4$ min and Triforine ${ }^{\mathrm{d}}$ & 85.9 & 16.6 & n.d. & n.d. \\
\hline $\mathrm{EtOH} / \mathrm{NaOCl} / \mathrm{EtOH}$ 5/5/5 min and Triforine $\mathrm{d}$ & 0.0 & 14.2 & n.d. & n.d. \\
\hline
\end{tabular}

\footnotetext{
${ }^{\text {a }}$ Treatments comprised 200 to 600 seeds.

${ }^{\mathrm{b}}$ Frequency of fungal outgrowth on malt extract agar. n.d. = not done.

${ }^{\mathrm{c}}$ Germination rate of seeds on sterile substrate.

${ }^{\mathrm{d}}$ Triforine was used at $0.1 \mathrm{mg} / \mathrm{ml}$ in malt agar plates (CFU) or included in the watering scheme (germination).
} 
used for this experiment (data not shown). However, the green parts of the seedlings appeared to be colonized to a lesser degree, especially the upper halves. Additionally, we performed PCR assays with primers ITS1F and ITS4, targeting all common fungi. DNA was isolated from two pools of 15 plantlets that were grown following surface-sterilization of seeds. In both cases, single bands of the same size resulted, which were directly sequenced. The electropherograms obtained yielded clean peak patterns that were identical to those from the 4/99-1 sequence (data not shown). This indicated that the targeted fungus was either the only one growing in the germlings analyzed or was predominant.

\section{Generation of aseptic host plants.}

We developed microcosms to study the influence of individual fungi on growth characteristics of the host by the initial elimination of all fungi from and the subsequent addition of single isolates to the system. Aseptic germlings grown in sterile soil from surface-sterilized seed were generated. Our procedures were adjusted to meet two criteria. First, the treatment should destroy all fungal propagules present on or in the seed. Second, it should still allow for reasonable germination rates of the seeds. To monitor the success of the treatments, we re-

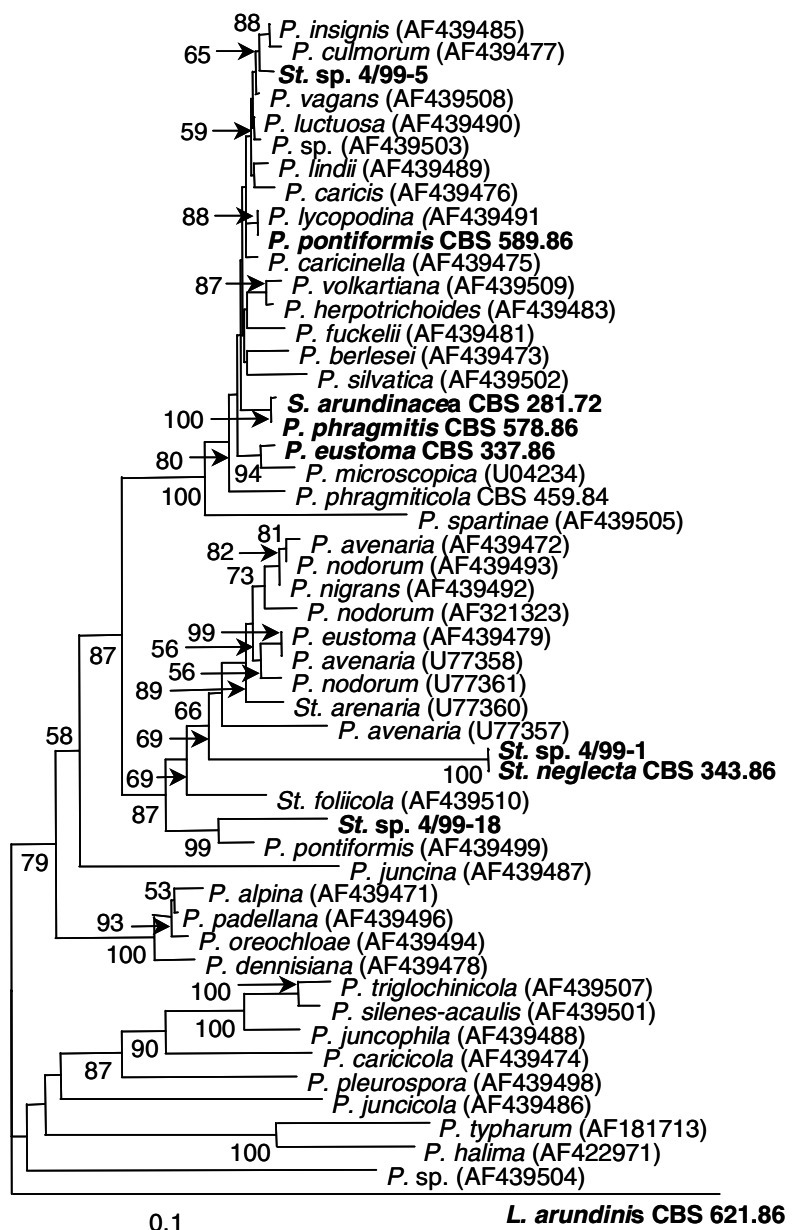

Fig. 1. Molecular phylogeny of Stagonospora and Phaeosphaeria spp. Distance tree displaying the relationships between three different types of ITS1-5.8S-ITS2 rDNA sequences from Stagonospora spp. (4/99-1, 4/99$5,4 / 99-18)$ isolated from seeds of Phragmites australis. Sequences established during this study are in bold type. References from EMBL and GenBank databases are in plain type. Accession numbers are given in parentheses. Bootstrap values of greater than $50 \%$ are indicated. Outgroup rooting is with Lophiostoma arundinis. $P .=$ Phaeosphaeria, St. $=$ Stagonospora, $L=$ Lophiostoma , and $S=$ Septoria . corded fungal outgrowth on malt agar and germination in soil. These tests were carried out with two sources of seeds, since we intended to use both in microcosms afterwards. One seed lot was harvested at Lake Constance, the other purchased from a commercial supplier. For the latter, succeeding treatments with $70 \% \mathrm{EtOH}, 5 \% \mathrm{NaOCl}$, and again with $70 \% \mathrm{EtOH}$, each lasting for $5 \mathrm{~min}$, was found satisfactory (Table 1). For the former, we needed to subsequently apply the fungicide Triforine to eliminate all fungi (Table 1). Complete absence of fungi from seedlings that grew in sterile soil for 24 days after these procedures had been applied was checked by two procedures. First, we isolated genomic DNA from pools of roots and shoots originating from 20 germlings and used it for PCR reactions with general fungal primers ITS1F and ITS4. Results for both seed sources showed that DNA generated with the optimized sterilization procedures did not produce PCR bands, whereas the milder treatments did (data not shown). In addition, for each treatment, eight seedlings were cut into small pieces that were put on malt agar plates. No colony arose in case of the optimized procedures (data not shown).

\section{Microcosm experiments.}

The first experiment was performed on germlings generated from seeds obtained from a commercial supplier. Besides our isolates 4/99-1 and 4/99-18, Stagonospora neglecta CBS 343.86 was included for reference (Fig. 1). There were two control series included. One was a blank, i.e., without any inoculum, the other was mock-inoculated with sterile malt agar pieces to check if the nutrients in the medium that was used to grow the fungi affected the outcome of the experiment. The microcosms were harvested and analyzed 23 weeks after inoculation. None of the fungi produced visible symptoms on the plants. Frequency of plant colonization was investigated by

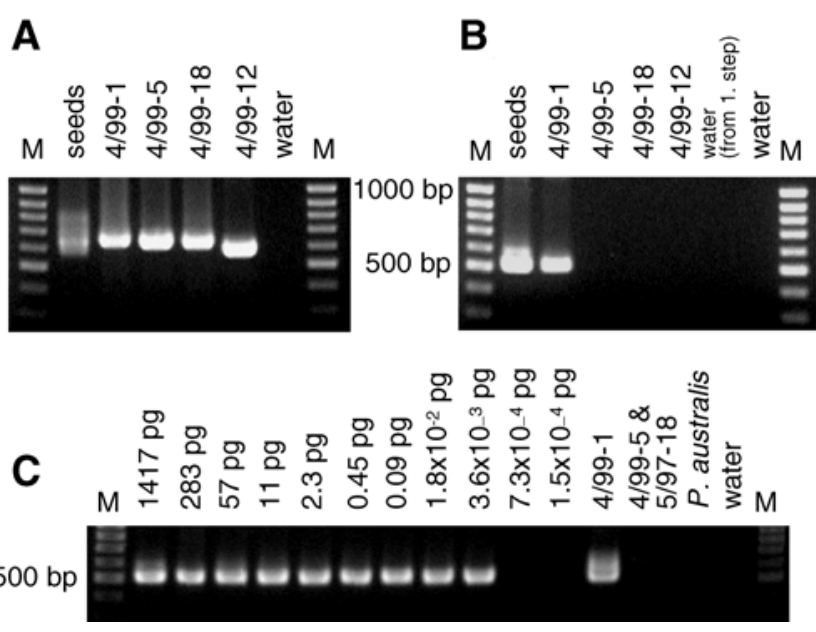

Fig. 2. Nested-polymerase chain reaction (PCR) assay for Stagonospora sp. (4/99-1 type). A, Specificity test, first step of nested-PCR with primers ITS1F and ITS4. Seeds: $300 \mathrm{ng}$ of template DNA isolated from a pool of 10 seeds harvested in November 2001 at the Reichenau location; strains 4/99-1, 4/99-5, 4/99-18, and 4/99-12: $50 \mathrm{ng}$ of fungal genomic DNAs from three species of Stagonospora and one Epicoccum sp., respectively; water: negative control. B, Specificity test, second step of nested PCR. Dilutions (500-fold) of the first reaction were amplified with primers targeting the ITS1- and ITS2-boxes of Stagonospora sp. strain 4/991. C, Sensitivity test, only second step of nested-PCR shown. Serial dilution of fungal genomic DNA of strain Stagonospora sp. strain 4/99-1 in a background of $80 \mathrm{ng}$ of DNA from aseptically grown Phragmites australis, lane 4/99-1 input of $4 \mathrm{ng}$ of pure DNA of the targeted fungus, lane 4/99-5 and 5/97-18 input of a mixture of $80 \mathrm{ng}$ of DNA from each of two nontarget fungi and lane $P$. australis input of $80 \mathrm{ng}$ of DNA from aseptically grown reed. All amounts are given as input for the first step of the nested PCR; the second step used a 100 -fold dilution of the first reaction. 
reisolating the fungi from tissue samples of roots and shoots on malt agar plates (Fig. 5). All fungi could be reisolated from unsterilized roots at high frequencies. Surface-sterilization moderately decreased the recovery rate in one case (4/99-1) and strongly decreased the same in the other two. Recovery from the lower halves of shoots was possible although, at low frequencies, recovery from the upper halves remained unsuccessful. Plant growth was clearly enhanced by the fungi present in the microcosms (Fig. 6). First, inoculation of any of the three fungi into the microcosm led to about twice as much biomass than that in the control (Fig. 7A). Second, cumulated culm lengths per plant were significantly increased (Fig. 7A), which resulted from higher average culm length and a higher number of culms per plant (not shown). Third, there was no significant difference in any parameter analyzed between the blanks and those plants that received sterile malt agar pieces (Fig. 7A).

In a second microcosm experiment, which was harvested 17 weeks after inoculation, we used aseptic germlings generated from seeds of Lake Constance habitats. Besides the three fungi used before, we included two additional, i.e., the third Stagonospora sp. isolated from reed seeds (4/99-5) and another reference strain, Phaeosphaeria phragmitis CBS 578.86 that had originally been isolated from $P$. australis. The control with sterile malt agar pieces was not included here. The results obtained were similar to the first experiment; all isolates increased biomass and cumulated stem lengths when compared with the control (Fig. 7B).

\section{Immunolocalization of a Stagonospora sp. in host tissues.}

The microcosms established during this work offered the unique opportunity to prove the endophytic state of individual, genetically defined fungi and to study their growth characteristics in the host. Plant tissues sampled from the microcosms that had been inoculated with Stagonospora sp. strain 4/99-1 were analyzed by immunofluorescence microscopy using an antibody raised against this fungus. Samples were only taken from those plants that allowed the recovery of the fungus (Fig. 5). We observed fungal hyphae proliferating between root epidermal cells and in contact with the first layer of cortical cells, demonstrating that the fungus had penetrated from the soil into the host, where it continued to grow endophytically (Fig. 8A). Hyphae grew straight, longitudinally to the root axis, without penetration of host cells; branching was rare. In the same way, we analyzed 9-week-old germlings that were raised in sterile soil from seeds sterilized by the procedure originally used to isolate these endophytes. As described above, these samples were also tested by the nested-PCR assay, which provided

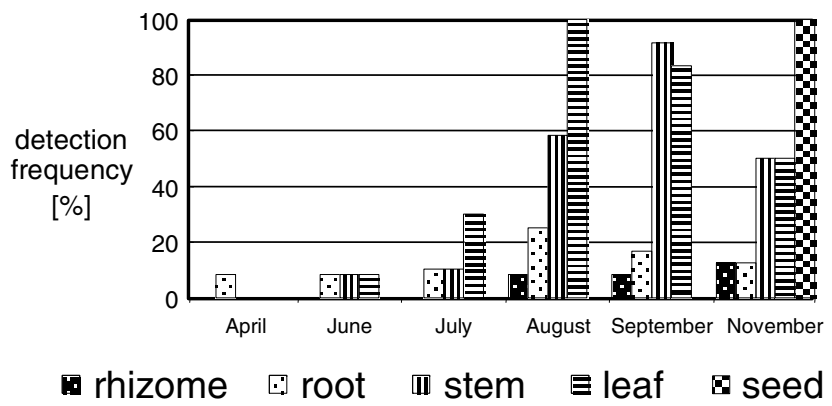

Fig. 3. Nested-polymerase chain reaction (PCR) assay on DNA from Phragmites australis grown at Lake Constance. Summary of 252 DNA preparations analyzed, originating from 70 plants. Detection frequency gives the percentage of respective tissue samples producing a band after the second step of the nested-PCR assay targeting Stagonospora sp. strain 4/991. Results were pooled from four sites at Lake Constance and over a period of three years. Seeds were tested as pools originating from several plants at the same site; all other tissue samples were tested as individual samples. information about their infection state (Fig. 4). Root growth patterns were similar to those from the above microcosms (not shown). Here, we also regularly observed single straight hyphae in stems (Fig. 8B) in which growth was below epidermal cells within parenchymous tissue. On occasion in leaves (not shown), long singular hyphae were found to grow through the parenchyma.

\section{DISCUSSION}

We have isolated three Stagonospora spp. from surface-sterilized seeds of $P$. australis and have investigated their influence on host vitality. Three independent experiments indicated that Stagonospora spp. are more prevalent in roots than in leaves. First, the nested-PCR assays on environmental samples indicated an early seasonal presence in roots and a delayed presence in leaves and stems. Second, we simulated a situation in which seeds harvested at Lake Constance would colonize a new site to initiate a new stand. The endophyte was frequently detected in roots of plantlets grown from those seeds but less frequently in lower shoot parts and least frequently in upper shoot parts. This indicated that the fungus is able, although slowly, to penetrate the shoot. Microscopy corroborated the endophytic growth of Stagonospora sp. strain 4/99-1 in these germlings. In comparison, colonization of Lolium perenne by Neotyphodium lolii excludes roots and appears to be synchronized with leaf extension (Tan et al. 2001). Furthermore, this experiment demonstrates that Stagonospora sp. (4/99-1 type) is carried by seeds as a viable propagule and can be vertically transmitted to the next generation of the host. The same type of transmission is found in Neotyphodium endophytes (Schardl and Clay 1997). Third, we simulated a situation in which fungal propagules would be present in the soil. These experiments were performed in microcosms with individual fungal isolates used to infect aseptic plantlets. After five months, recovery rates from surface-sterilized roots were again higher than that from green parts. Microscopy confirmed that Stagonospora sp. (4/99-1 type) did penetrate into host tissues, where it continued to grow endophytically.

These findings suggest that the fungus might persist systemically. It would overwinter in roots of its perennial host and would slowly grow upwards during the season. By the end of the growth period, it would enter the seeds, which are only used to colonize new sites, since mature reed stands advance vegetatively by rhizomes. Fungal propagules remaining in the roots would start the cycle the following spring again. Alternatively, the fungus might overwinter on fallen shoots. This

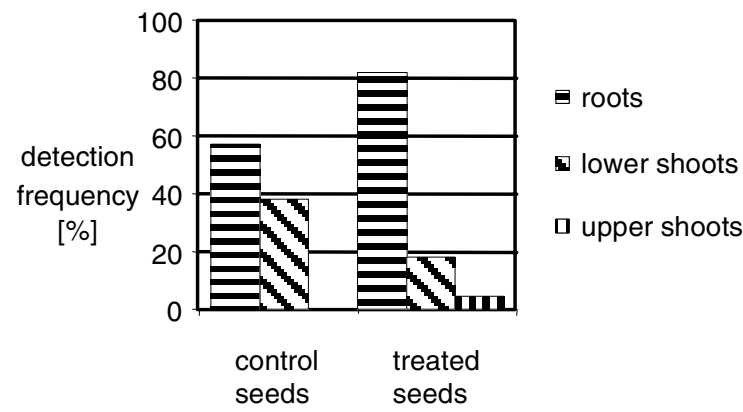

Fig. 4. Nested-polymerase chain reaction (PCR) assay on DNA from Phragmites australis grown in microcosms. Detection frequency gives the percentage of samples producing a band after the second step of the nested-PCR assay targeting Stagonospora sp. strain 4/99-1. Assays were performed on DNA isolated from the indicated tissue samples of 9-weekold plants grown in aseptic microcosms. Plants originated from untreated or surface-sterilized seeds $(\mathrm{EtOH} / \mathrm{NaOCl} / \mathrm{EtOH}$ for 1:2:1 min) harvested at Lake Constance. Each group consisted of 21 individuals analyzed. 
would provide the inoculum to initially infect roots in spring. In addition, we cannot exclude the possibility that Stagonospora spp. sporulate under natural conditions that could contribute to the wide-spread infection of reeds in autumn. Future experiments will need to broaden these studies, in order to fully uncover the life cycle of these endophytes.

Most investigations on fungal endophytes have focused on the description of their diversity and their distribution in natural vegetation. With the exception of the genus Neotyphodium and its relatives, little is known about functional contributions of seed-borne endophytes. In general, a given endophyte does not occupy a whole plant by the exclusion of all other competing fungi. This is even the case for Neotyphodium spp., since it has been shown that they can occur cosymbiotically with socalled p-endophytes, which were also referred to as Phialophora-like and Gliocladium-like isolates and still await a detailed investigation (An et al. 1993; Latch et al. 1984). Interestingly, these endophytes, which are unrelated to Stagonospora spp., appear to be seed-transmitted as well. At the same time therefore, several beneficial, pathogenic, or both fungi might colonize the same plant and, in addition, antagonistic, synergistic, or both interactions might exist between them. This explains the difficulties in establishing rigorous experimental conditions to test single plant-fungus interactions. We applied a microcosm approach to overcome this limitation. It was designed to generate a sterile environment harboring plants without any associated fungi, which was confirmed by PCR and isolation procedures. These microcosms were then inoculated with individual fungi that had been isolated from the same host. All three Stagonospora species isolated from common reed growing at Lake Constance significantly enhanced the biomass of the host. Inspection of the literature retrieved two older citations - besides those on Neotyphodium spp.- - reporting about fungi that were apparently seed-transmitted and enhanced the biomass of their hosts. One reported that the fungus Phomopsis casuarinae systemically infecting Casuarina equisetifolia improved vigor of seedlings (Bose 1947). Another reported an unidentified fungus in the seeds of Helianthemum chamaecistus and it seemed that vigor of the germlings correlated with the presence of the fungus (Griffith Boursnell 1950). Through the application of modern techniques that were not available then, we can now establish a strict linkage between the inoculation of a seed-borne endophyte into the microcosm, the growth of the fungus in plant tissues, and an enhanced growth response of the host.

One advantage of our microcosm approach was that it allowed us to unambiguously prove the endophytic state of Stagonospora sp. (4/99-1 type) by microscopy, which would have been difficult with tissue samples from natural habitats where several fungi colonize the same host at the same time.

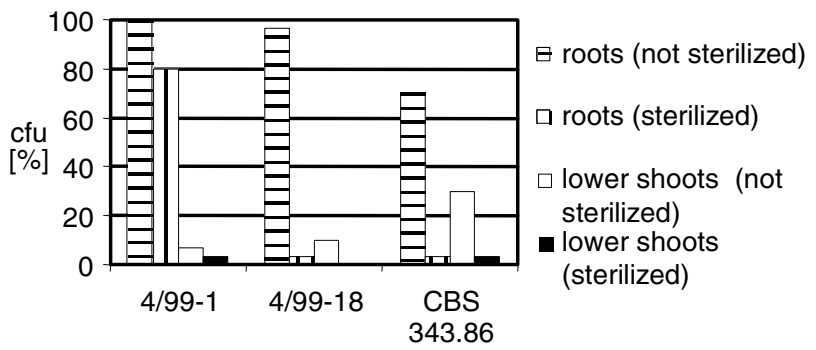

Fig. 5. Reisolation of Stagonospora spp. from reed microcosms. CFU gives the percentage of samples that produced outgrowth of the inoculated strain on malt agar plates. From each microcosm, surfacesterilized $(\mathrm{EtOH} / \mathrm{NaOCl} / \mathrm{EtOH}$ for 1:2:1 min), and untreated tissue pieces were tested. Each bar represents the results from 30 samples analyzed; upper shoot samples did not give colonies.
Another advantage was the exclusion of other factors, such as grazers, insects, nematodes, or additional fungi, that could influence the outcome of such experiments. The only difference between treatments was the presence of a single fungal inoculum. It seems remarkable that an endophyte, which is a bona fide sink for host-produced photosynthates, generated these beneficial effects. The microcosms were substrate-limited, since addition of fertilizer into the watering scheme boosted reed biomass (M. Ernst, unpublished data). Therefore, an obvious explanation for enhanced biomass is that the endophyte acted in a way similar to mycorrhizal fungi. Since discussions do not appear to be settled yet to account for this effect in Neotyphodium-type endophytes (Arachevaleta et al. 1989; Malinowski et al. 2000; Marks and Clay 1996), we do not rule out alternative mechanisms.

In conclusion, results obtained from artificial microcosms might indicate that Stagonospora endophytes carried by seeds might provide a competitive advantage to germlings during the establishment of new reed stands. We believe that other seedtransmitted fungal endophytes with similar features could have a greater ecological importance than commonly anticipated.

\section{MATERIALS AND METHODS}

Plant and fungal materials.

Samples of $P$. australis originated from the sites at Lake Constance that had been described (Wirsel et al. 2001). Samples were harvested from August 1998 to August 2001. Sampling of reed, cultivation, and storage of fungal cultures were performed as outlined earlier (Wirsel et al. 2002). Seed-borne

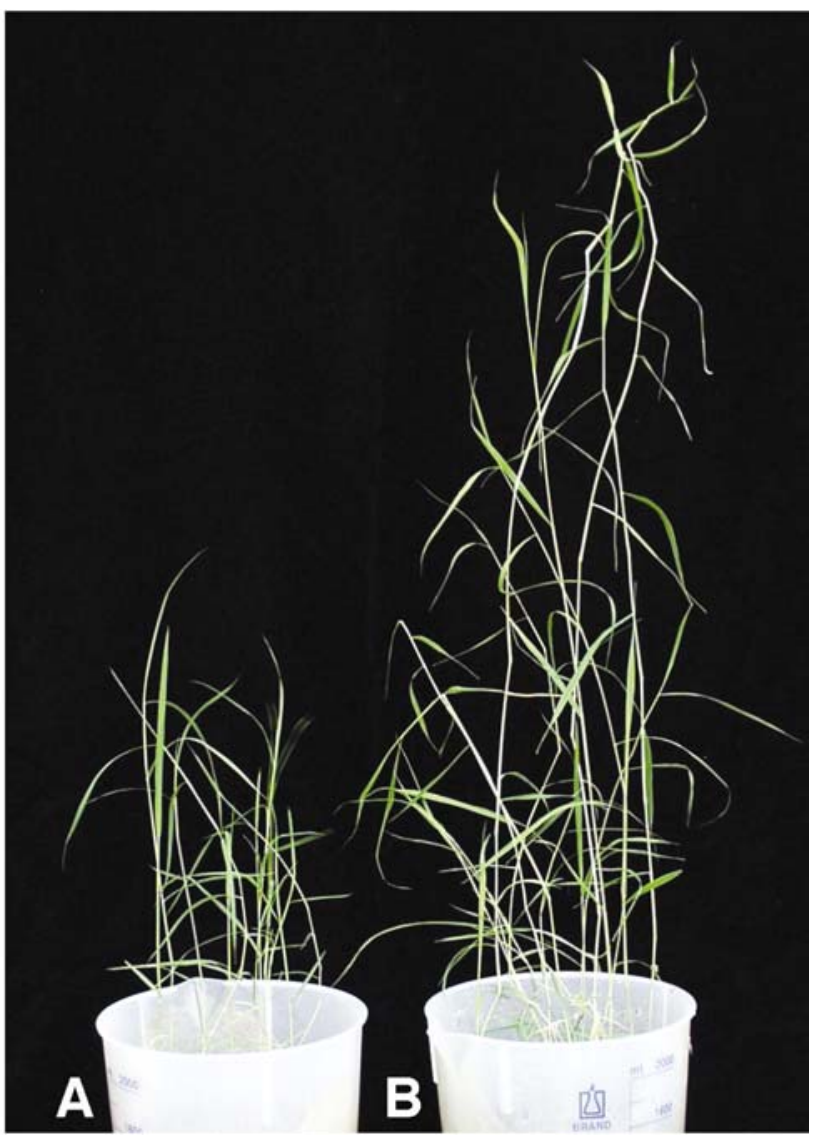

Fig. 6. Effect of Stagonospora spp. on growth of Phragmites australis in microcosms. Plants shown were from the first microcosm experiment (commercial source of seeds). A, Control (no inoculum), B, inoculation with Stagonospora sp. strain 4/99-1. 
isolates originate from harvests in November 1998 at the flooded Reichenau location. For their isolation, seeds were successively treated with $70 \%$ ethanol for $1 \mathrm{~min}, 5 \%$ sodium hypochlorite for $2 \mathrm{~min}$, and $70 \%$ ethanol for $1 \mathrm{~min}$. Alternative treatments initially tried are given above and in Table 1. After three final rinses for 2 min each in sterile deionized water, seeds were placed on malt agar plates and were incubated in the dark at $20^{\circ} \mathrm{C}$. Sporulation of isolates 4/99-5 and 4/99-18 was accomplished on autoclaved heads of barley on synthetic nutrient agar (Nirenberg 1976) at $20^{\circ} \mathrm{C}$ under permanent UV light. Fungal reference cultures were purchased from the Centraal Bureau voor Schimmelcultures (CBS, Utrecht, The Netherlands). Reference seed of $P$. australis was purchased from Jelitto Staudensamen $\mathrm{GmbH}$ (Schwarmstedt, Germany).

\section{DNA extraction, PCR, sequencing, and phylogenetic analysis.}

DNA preparations from fungal mycelia and from plant tissue and single-step PCR reactions targeting either all fungi using the primer pair ITS1F and ITS4 or the host with primers $\mathrm{Pa}$ ITS.F1 and Pa-ITS.R1, respectively, were performed as previously described (Wirsel et al. 2002). A nested-PCR assay to detect Stagonospora sp. strain 4/99-1 was used for the first reaction primers ITS1F and ITS4. The second amplification step relied on primers annealing at the highly variable ITS1- and ITS2 boxes of the targeted fungus. Primers were 4/99-1/ITS.F1 (5' tga gga gtc cet aaa aag ac) and 4/99-1/ITS.R1 (5' aaa agg ctt gtg gat $\mathrm{gc}$ ). Reaction mixtures were generally as described
(Wirsel et al. 2002) and included $0.25 \mu \mathrm{l}$ of the first PCR in a volume of $25 \mu \mathrm{l}$. Cycling parameters for the second step were as follows: initial denaturation at $94^{\circ} \mathrm{C}$ for $2.5 \mathrm{~min}$ and $10 \mathrm{cy}-$ cles of a touch-down PCR protocol: $94^{\circ} \mathrm{C}$ for $30 \mathrm{~s}, 75^{\circ} \mathrm{C}$ for 15 $\mathrm{s}$ with a decrease of $1^{\circ} \mathrm{C}$ per cycle, $72^{\circ} \mathrm{C}$ for $30 \mathrm{~s}$, immediately followed by 39 cycles of $94^{\circ} \mathrm{C}$ for $30 \mathrm{~s}, 65^{\circ} \mathrm{C}$ for $15 \mathrm{~s}, 72^{\circ} \mathrm{C}$ for $30 \mathrm{~s}$ plus one additional second per cycle. Positive and negative controls included pure genomic DNA of target and nontarget fungi, respectively. Generation and analysis of DNA sequences were carried out as described (Wirsel et al. 2002). Phylogenetic analysis used the BioNJ algorithm implemented in the program PAUP Version 4.0.b10 (Swofford 2000) and the Kimura 2 parameter for distance measures. The confidence of the tree was estimated with 1,000 bootstrap replicates.

\section{Generation}

of aseptic seedlings and microcosm experiments.

Substrate to grow $P$. australis was a 1:1:1 mixture of washed sand (Meichle \& Mohr GmbH, Konstanz, Germany), garden soil (Gebrüder Patzer GmbH, Sinnpal-Jossa, Germany), and clay (Bauamt Konstanz, Germany) that was autoclaved twice ( $2 \times 90 \mathrm{~min}$ at $121^{\circ} \mathrm{C}$ with a resting period of 2 days). Autoclaving either took place in glass dishes $(20-\mathrm{cm}$ diameter, $5-\mathrm{cm}$ height) containing $500 \mathrm{ml}$ of substrate and $120 \mathrm{ml}$ of deionized water or in plastic beakers (14-cm diameter, $18.5-\mathrm{cm}$ height) that were filled with $1,200 \mathrm{ml}$ of substrate and $300 \mathrm{ml}$ of deionized water and covered with a glass dish. Sterility of the substrate was controlled by inoculation of malt agar plates.

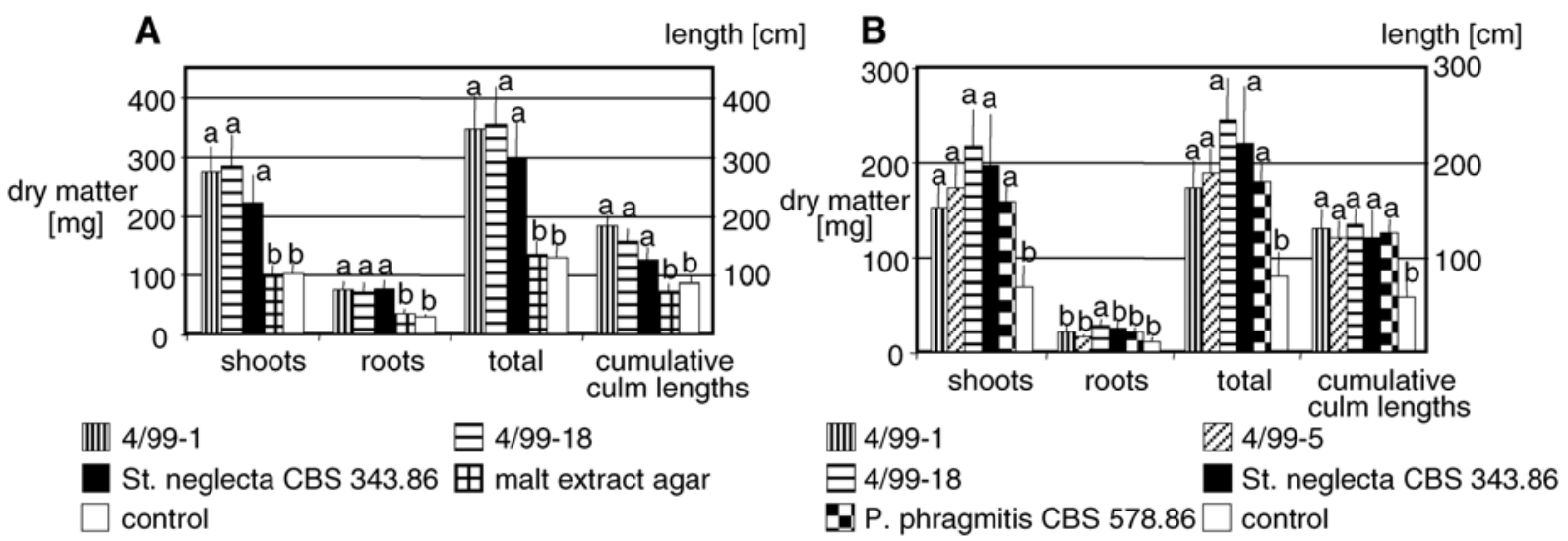

Fig. 7. Plant growth parameters recorded in microcosm experiments. A, First microcosm experiment: commercial source of seeds used to generate aseptic germlings. Results shown are based on the analysis of 14 plants for each treatment 23 weeks after inoculation. B, Second microcosm experiment: aseptic germlings were generated from seeds harvested at Lake Constance habitats. Results shown are based on the analysis of 12 plants for each treatment 17 weeks after inoculation with the indicated fungi. A, and B, Average root, shoot, and total dry matter, as well as cumulated culm lengths per plant. Bars on top of the columns represent the mean standard errors. Values being significantly different from the control (no inoculum) are indicated by the letter a on top of the column; b indicates nonsignificance.
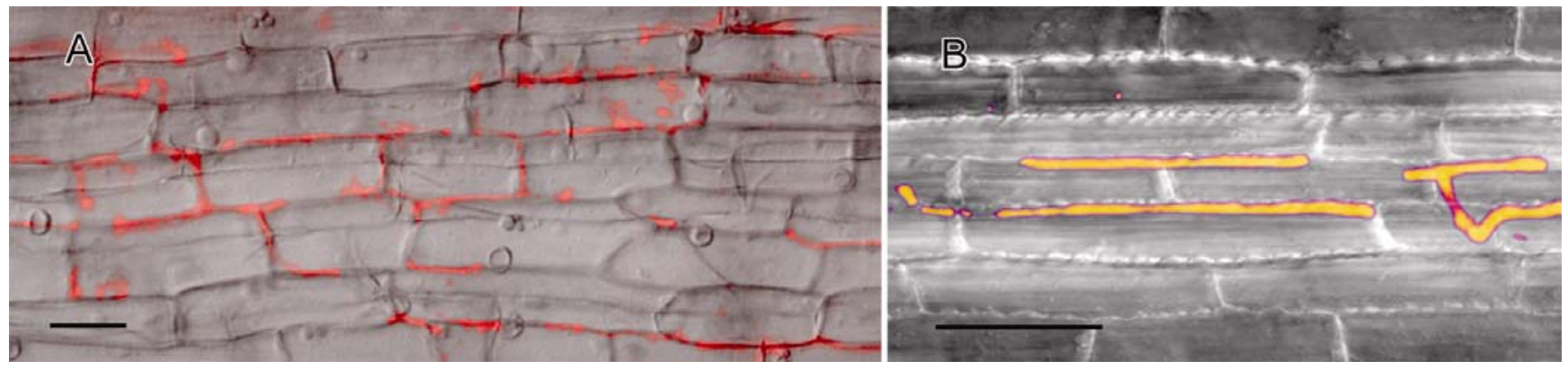

Fig. 8. Immunofluorescence microscopy. A, Root from Phragmites australis grown in a microcosm with Stagonospora sp. strain 4/99-1. Plants originated from the first microcosm experiment. B, Stem from $P$. australis grown in an aseptic microcosm without additional inoculum. Plants were raised from surface-sterilized seeds to allow survival of endophytes. Harvest was at 9 weeks. Detection was with a primary antibody directed against $4 / 99-1$ mycelia and a secondary antibody (anti rabbit with Cy3-label). Bars $=20 \mu \mathrm{m}$. 
Seeds were surface-sterilized as outlined above with each of the three treatments lasting $5 \mathrm{~min}$. Afterwards, they were placed in lots of about 300 in the glass dishes. These were kept for 50 days in a growth chamber adjusted to a $16 \mathrm{~h}$ cycle of light at $24^{\circ} \mathrm{C}$ and $8 \mathrm{~h}$ of darkness at $20^{\circ} \mathrm{C}$. Regular white light was used for illumination (Osram L58W/25 Universal-White, München, Germany). Under sterile conditions, sterile deionized water was added biweekly to keep the substrate well wetted. In the case of seeds harvested at Lake Constance the water contained the fungicide Triforine (Cyanamid Agrar GmbH \& Co. KG, Schwabenheim, Germany) at an effective concentration of $0.1 \mathrm{mg} / \mathrm{ml}$, to kill surviving fungal propagules (discussed above). Each lot of germlings used for further experiments was tested for sterility by harvesting several seedlings at random under sterile conditions and inoculating tissue pieces on malt agar plates. Initially, PCR reactions with primers ITS1F and ITS4 also were performed on DNA preparations obtained from pools of seedlings, to test for the absence of fungi.

Microcosm experiments were carried out in the beakers described above. Pregrown aseptic germlings were transplanted from the glass dishes under sterile conditions. Each treatment used four beakers, each containing three to four germlings. Temperature and light regimes were as described above. Light intensities measured at soil level were 55 to $60 \mu \mathrm{E} / \mathrm{m}^{2} \mathrm{~s}$. The positions of the beakers were rotated at random every other week between the three growth chambers used in these experiments. Sterile deionized water was added as needed; it did not contain fungicides or fertilizer. For the first microcosm experiment, plants grew for an additional 30 days before inoculation with fungi; for the second experiment, inoculation followed immediately. Fungal inoculum consisted of fresh mycelia on 20 malt agar pieces $(0.7 \times 0.7 \mathrm{~cm})$ that were put on the soil so that they remained within a distance of 1 to $2 \mathrm{~cm}$ to the germlings. After 6 weeks, the glass lids were replaced by translucent plastic bags $(30-\mathrm{cm}$ diameter, $70-\mathrm{cm}$ height). Incubation was for up to five months after fungal inoculation.

At the end of the experiments, small samples from roots and green tissues were taken under sterile conditions and either surface-sterilized with the same procedure used for initial fungal isolation or in a control just washed with sterile water, followed by inoculation of malt agar. Additional samples were prepared for microscopy. Compared with total biomass, the samples taken were negligible. The length of each culm originating from individual root stocks was recorded, and the biomasses for roots and shoots were determined separately after drying for 2 days at $80^{\circ} \mathrm{C}$. Statistical evaluation of growth parameters is based on the combined results of all plants of a given treatment. It was performed by Dunnett's test with $95 \%$ confidence limits, using the JMP program version 4.04 (SAS Institute, Cary, NC, U.S.A.).

\section{Production of antibodies}

against Stagonospora spp. and immunocytochemistry.

Mycelium from strain 4/99-1 was grown for 6 days in 400 ml of liquid RNT medium (Rao and Niederpruem 1969), was harvested on paper filter, and was washed with sterile distilled water. It was frozen in liquid nitrogen and pulverized. Sterile distilled water was added $(5 \mathrm{ml}$ per $\mathrm{ml}$ of the resulting powder), and $500-\mu \mathrm{l}$ aliquots were stored at $-20^{\circ} \mathrm{C}$. A female SPF New Zealand white rabbit was immunized with one aliquot mixed with $500 \mu \mathrm{l}$ of complete Freund adjuvant. Biweekly, the animal received three boosts using mycelial aliquots and $500 \mu \mathrm{l}$ of incomplete Freund adjuvants. Serum was collected 26 days after the third boost. A preadsorption to mycelial preparations from unrelated fungi was conducted to remove antibodies recognizing unspecific epitopes. For this purpose, mycelial powders were generated from strains 6/97-11, 5/97-12, 5/97-19,
$315 \mathrm{~W}$, and 5/97-54, which were originally isolated from vegetative tissues of $P$. australis (Wirsel et al. 2001). A homogenous mix of these powders was added to an equal volume of PBS (phosphate buffered saline, $\mathrm{pH}$ 7.2) and autoclaved. Afterwards, the suspension was centrifuged, and pellets were washed three times with one $\mathrm{ml}$ of PBS. Resulting pellets were stored at $-20^{\circ} \mathrm{C}$. Preadsorption was carried out just prior to microscopy by mixing one volume of serum with half a volume of PBS and half a volume of the mycelial mix from unrelated fungi. Incubation was for $10 \mathrm{~min}$ at ambient temperature, followed by centrifugation for $10 \mathrm{~min}$ at $14,000 \mathrm{rpm}$. Resulting supernatants were used for microscopy.

Preparation of plant tissue samples and immunological detection of fungal structures was essentially carried out as described (Sohn et al. 2000). Microphotographs were taken with a Zeiss Axioplan 2 microscope and Axiocam camera (Fig. 8A) or a Zeiss LSM 510 microscope (Fig. 8B), using either DIC interference contrast mode or fluorescence mode with appropriate filters for $\mathrm{Cy} 3$. Interference contrast and fluorescence micrographs were superimposed using Adobe Photoshop.

\section{ACKNOWLEDGMENTS}

Financial support was provided by the Deutsche Forschungsgemeinschaft through SFB 454. We thank A. Leuchtmann (ETH Zürich) for help identifying isolates, R. Bänninger for technical support, W. Nagl for help with statistics, and R. T. Voegele for help with antibody production (all at Universität Konstanz). We express our gratitude to R. T. Voegele for critically reading the manuscript.

\section{LITERATURE CITED}

An, Z. Q., Siegel, M. R., Hollin, W., Tsai, H. F., Schmidt, D., and Schardl, C. L. 1993. Relationships among non-Acremonium sp. fungal endophytes in five grass species. Appl. Environ. Microbiol. 59:15401548 .

Arachevaleta, M., Bacon, C. W., Hoveland, C. S., and Radcliffe, D. E. 1989. Effect of the tall fescue endophyte on plant response to environmental stress. Agron. J. 81:83-90.

Bose, S. R. 1947. Hereditary (seed-borne) symbiosis in Casuarina equisetifolia Forst. Nature 159:512-514.

Carroll, G. C. 1988. Fungal endophytes in stems and leaves: From latent pathogen to mutualistic symbiont. Ecology 69:2-9.

Clay, K. 1992. Fungal endophytes of plants: Biological and chemical diversity. Natural Toxins 1:147-149.

Cunfer, B. M., and Ueng, P. P. 1999. Taxonomy and identification of Septoria and Stagonospora species on small-grain cereals. Annu. Rev. Phytopath. 37:267-284.

Griffith Boursnell, J. 1950. The symbiotic seed-borne fungus in the Cistaceae. Annals Bot. 14:217-243.

Groppe, K., Steinger, T., Sanders, I. I., Schmid, B., Wiemken, A., and Boller, T. 1999. Interaction between the endophytic fungus Epichlö bromicola and the grass Bromus erectus: Effects of endophyte infection, fungal concentration and environment on grass growth and flowering. Mol. Ecol. 8:1827-1835.

Hodge, A., Campbell, C. D., and Fitter, A. H. 2001. An arbuscular mycorrhizal fungus accelerates decomposition and acquires nitrogen directly from organic material. Nature 413:297-299.

Landeweert, R., Hoffland, E., Finlay, R. D., Kuyper, T. W., and van Breemen, N. 2001. Linking plants to rocks: Ectomycorrhizal fungi mobilize nutrients from minerals. Trends Ecol. Evol. 16:248-254.

Latch, G. C. M., Christensen, M. J., and Samuels, G. J. 1984. Five endophytes of Lolium and Festuca in New Zealand. Mycotaxon 20:535550 .

Latch, G. C. M., Hunt, W. F., and Musgrave, D. R. 1985. Endophytic fungi affect growth of perennial ryegrass. NZ. J. Agric. Res. 20:165168.

Leuchtmann, A. 1992. Systematics, distribution, and host specificity of grass endophytes. Natural Toxins 1:150-162.

Malinowski, D. P., Alloush, G. A., and Belesky, D. P. 2000. Leaf endophyte Neotyphodium coenophialum modifies mineral uptake in tall fescue. Plant Soil 227:115-126.

Marks, S., and Clay, K. 1996. Physiological responses of Festuca arundinacea to fungal endophyte infection. New Phytol. 133:727-733.

Nirenberg, H. 1976. Untersuchungen über die morphologische und biolo- 
gische Differenzierung in der Fusarium-Sektion Liseola. Mitteilungen aus der Biologischen Bundesanstalt für Land- und Forstwirtschaft. Berlin Dahlem 169:1-117.

Petrini, O., Sieber, T. N., Toti, L., and Viret, O. 1992. Ecology, metabolite production, and substrate utilization in endophytic fungi. Natural Toxins 1:185-196.

Rao, P. S., and Niederpruem, D. J. 1969. Carbohydrate metabolism during morphogenesis of Coprinus lagopus (sensu Buller). J. Bacteriol. 100:1222-1228.

Schardl, C. L. 2001. Epichlö festucae and related mutualistic symbiont of grasses. Fungal Genet. Biol. 33:69-82.

Schardl, C. L., and Clay, K. 1997. Evolution of mutualistic endophytes from plant pathogens. In The Mycota V Part B (G. C. Carroll, and P. Tudzynski, Eds.), Springer, Berlin, Germany.

Sharma, S., Madan, M., and Vasudevan, P. 1997. Biology and applications of mycorrhizal fungi. Microbiol. 13:427-436.
Sohn, J., Voegele, R. T., Mendgen, K., and Hahn, M. 2000. High leve activation of vitamin B1 biosynthesis genes in haustoria of the rust fungus Uromyces fabae. Mol. Plant-Microbe Interact. 13:629-636.

Swofford, D. L. 2000. PAUP*. Phylogenetic Analysis Using Parsimony (* and Other Methods), Sinauer, Sunderland, MA, U.S.A.

Tan, Y. Y., Spiering, M. J., Scott, V., Lane, G. A., Christensen, M. J., and Schmid, J. 2001. In planta regulation of extension of an endophytic fungus and maintenance of high metabolic rates in its mycelium in the absence of apical extension. Appl. Environ. Microbiol. 67:5377-5383.

Wirsel, S. G. R., Leibinger, W., Ernst, M., and Mendgen, K. 2001. Genetic diversity of fungi closely associated with common reed. New Phytol. 149:589-598.

Wirsel, S. G. R., Runge-Froböse, C., Ahren, D. G., Kemen, E., Oliver, R. P., and Mendgen, K. W. 2002. Four or more species of Cladosporium sympatrically colonize Phragmites australis. Fungal Genet. Biol. 35:99-113. 